\title{
Upcycled Duo: Combating Over-Consumption and Apparel Waste Through Clothes People Already Own
}

\author{
Aline Gomes Siqueira, Katie Ellis, and Kelly Cobb, University of Delaware, Newark, DE
}

Most people who go to the thrift store do so out of monetary benefit (Cervellon et al., 2012), but no matter the income, people thrift their discarded items or throw them away (Weber et al., 2017). Consumption and disposal patterns of consumers and industries have a profound effect on the deterioration of the environment. A recent report from the United States Environmental Protection Agency showed that landfills receive, on average, 10.5 million tons of municipal solid waste textiles (Textiles: Material-Specific Data, 2019). Textile waste accounted for 7.6 percent of all municipal solid waste landfilled. Only $30 \%$ of the total textile waste was diverted from landfills by the recycling industry (Textiles: Material-Specific Data, 2019). Landfilling is the main form of waste management in the United States, and the environmental fate of textiles in landfills depends on fiber material. Textile waste is not usually considered an issue in waste management because textile waste often is not regarded as toxic (Weber et al., 2017). Education and involvement of consumers in sustainable practices are necessary for the health of our planet. There is a general lack of knowledge from the consumers of how and where to dispose of clothing and still appears to be little awareness of the impact of the disposition of high volumes of textile waste (Morgan \& Birtwistle, 2009).

The purpose of this design research was to vision a sustainable fashion service model, functioning to reinvigorate unused clothing, by design. Applying IDEO design thinking methodology (as part of a class activity on creative research methods) student researchers conducted discovery, creative research and design prototyping of an engagement model involving the re-interpretation of products, focusing on reconnecting consumers to the way they make, use and dispose of clothing, inspiring tangible changes in the public's awareness or education on the consumption, used and disposal of textiles (Cobb, 2020).

Through the use of IDEO creative thinking methodology, the team of student researchers collected data from thrift users and high-income consumers for inspiration. Followed by the ideation phases, the team developed a "how might we..." statement, how might we encourage higher-income individuals to upcycle their clothes? To address the question, the team developed a sustainable fashion service model via a community-based upcycling service named DUO. The researchers developed a protocol for redesign including collection service, consumer style guide, procedures for re-design, delivery and feedback. In this scenario, disposal of unused clothing is by-passed. For example, instead of a consumer thrifting unused items or disposing of them, they would send them to DUO, the consumer would fill out a style guide (including consumer preference, sizing and fit and optional narrative) The item was analyzed and re-designed using upcycling techniques. The DUO re-design was delivered to the consumer. If approved, the consumer paid an up-cycling fee. If not, the item was collected to be sold on the DUO website. To test this innovative sustainable fashion service model, researchers engaged class peers and faculty to participate in sustainable fashion service pilot. During post-test reflections participants reflected on "finding enjoyment when receiving a new item" and felt "satisfaction at actively lowering the footprint of their clothing use." Future research will further contribute to sustainable design initiatives, with a special focus on extending use and care of clothing by involving the broader community in a more rigorous design pilot (masters design thesis) to further explore the upcycle market by better understanding consumers' awareness and interest 


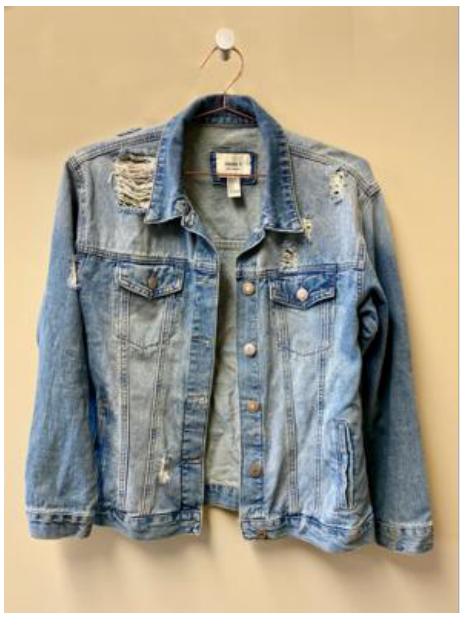

a.

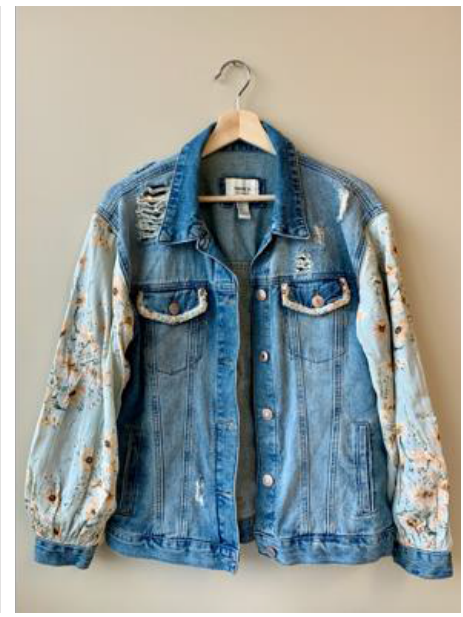

b.

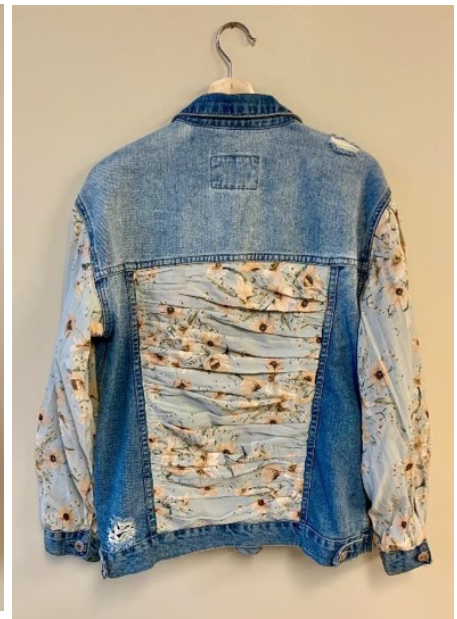

c.

Figure 1: Denim and Cotton pilot study with up-cycling outcomes (a. before, b. and c. after)

Figure 2: Linen and Printed Cotton study with up-cycling outcomes (d. before, e. and f. after)

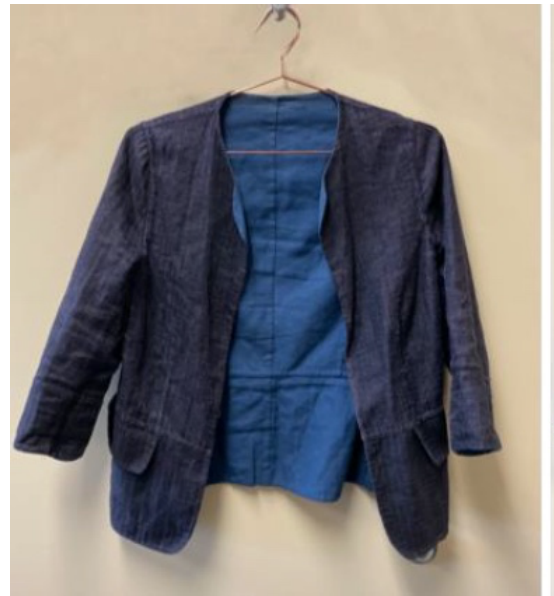

d.

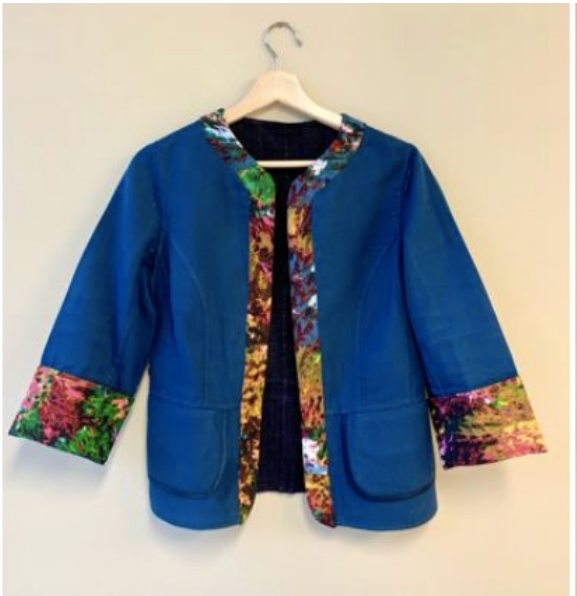

e.

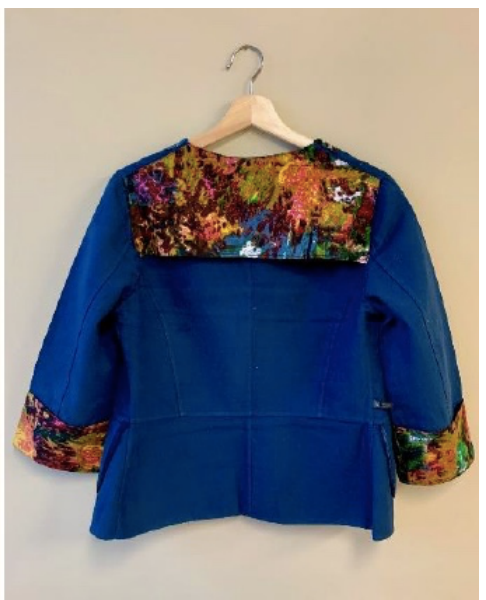

f.

Figure 3: Knitted study with up-cycling outcomes (g. before and h. after)

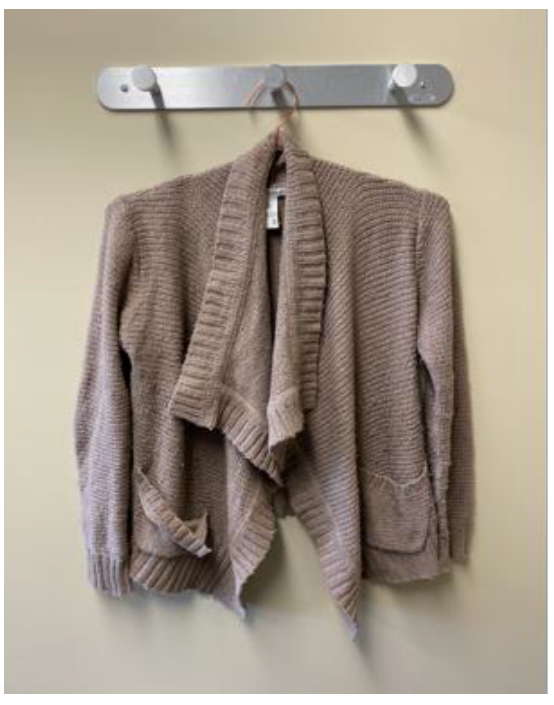

g.

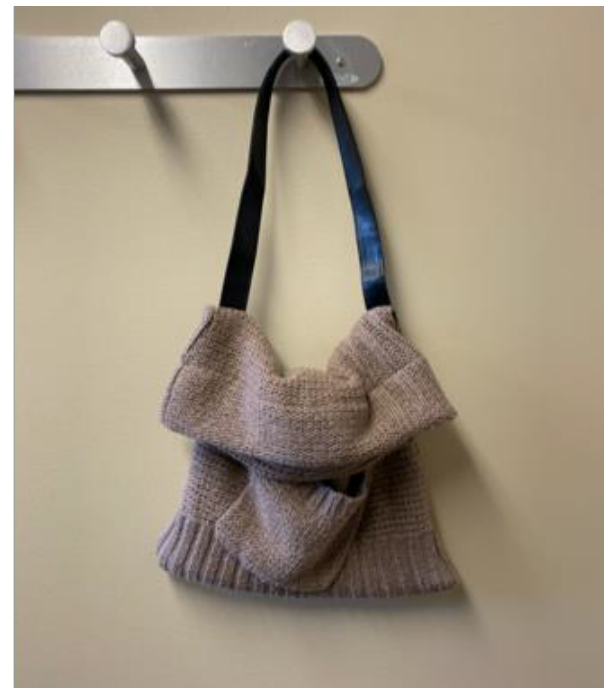

h. 


\section{References}

Cervellon, M.-C., Carey, L., \& Harms, T. (2012). Something old, something used: determinants of women's purchase of vintage fashion vs second-hand fashion. International Journal of Retail and Distribution Management, 40(12), 956974. doi: 10.1108/09590551211274946

Cobb, K., \& Keough, K. (2020, March). Redesigning Fashion's Future Through Community Engagement: A Circular Textile Pilot In Collaboration with Goodwill of Delaware and Delaware County. Presented at the Provost Symposium of Community Engaged Scholarship, University of Delaware. Retrieved from https://www.cei.udel.edu/

Ellen MacArthur Foundation, A new textiles economy: Redesigning fashion's future. (2017, http://www.ellenmacarthurfoundation.org/publications).

Morgan, L. R., \& Birtwistle, G. (2009). An investigation of young fashion consumers' disposal habits. International Journal of Consumer Studies, 33(2), 190-198. doi: 10.1111/j.1470-6431.2009.00756.

Textiles: Material-Specific Data. (2019, May 7). Retrieved November 4, 2019 , from https://www.epa.gov/facts-and-figures-about-materials-waste-andrecycling/textiles-material-specific-data.

Weber, S., Lynes, J., \& Young, S. B. (2017). Fashion interest as a driver for consumer textile waste management: reuse, recycle or disposal. International Journal of Consumer Studies, 41(2),

(c) 2020 The author(s). Published under a Creative Commons Attribution License (https://creativecommons.org/licenses/by/4.0/), which permits unrestricted use, distribution, and reproduction in any medium, provided the original work is properly cited.

ITAA Proceedings, \#77- https: //itaaonline.org 